\title{
Trajetória e Implementação de Disciplina Interprofissional para cursos da Área de Saúde
}

Edson Arpini Miguel, Angélica Maria Bicudo, Najara Rocha, Rozilda Neves Alves, Adriana Meyer Albiero

\section{Resumo}

Introdução: Na Educação Interprofissional duas ou mais profissões de saúde aprendem uma sobre a outra, aprimorando atitudes, conhecimento, habilidades e comportamentos para a prática colaborativa. Na Universidade Estadual de Maringá (UEM) os cursos de saúde apresentam currículos com disciplinas, hierarquizados e centrados no professor. Justificam- se mudanças em busca de uma formação integral. Objetivo: Este trabalho descreve a criação e implementação de disciplinas interprofissionais que atuam na Atenção Primária em Saúde (APS). Método: Os componentes curriculares denominados Atenção em Saúde I e II foram introduzidos, de forma obrigatória, na matriz curricular nos cursos de Medicina, Enfermagem, Odontologia, Farmácia, Educação Física, Biomedicina e Psicologia. O total de estudantes matriculados é de aproximadamente 440 por ano, com 42 professores/tutores vinculados às disciplinas. Nas atividades é utilizada problematização, conforme tutorial previamente construído pelos docente e profissionais dos serviços. Resultados: Os estudantes em grupos, pelo menos um de cada curso, tem como cenários de ensino a rede APS. O total de alunos que cumpriram a disciplina está em torno de 1500 com 140 projetos de intervenção executados. A avaliação formativa é composta de eixos cognitivos, psicomotor e afetivo, articulados, contínuos e sistemáticos. Conclusão: a inovação da interprofissionalidade na graduação na primeira série dos cursos tem proporcionado maior integração entre os estudantes e realização de práticas colaborativas, além da aproximação da universidade com os serviços de saúde.

Descritores: educação, currículo, avaliação, metodologias ativas saúde 